\title{
BIBLIOTECAS UNIVERSITÁRIAS DAS INSTITUIÇÕES ESTADUAIS DE ENSINO SUPERIOR PARANAENSES E A MEDIAÇÃO DA INFORMAÇÃ̃ NO FACEBOOK
}

\author{
UNIVERSITY LIBRARIES OF STATE INSTITUTIONS OF HIGHER EDUCATION \\ OF PARANÁ AND MEDIATION OF INFORMATION ON FACEBOOK
}

BIBLIOTECAS UNIVERSITARIAS DE LAS INSTITUCIONES ESTADUALES DE ENSEÑANZA SUPERIOR PARANAENSES Y LA MEDIACIÓN DE LA INFORMACIÓN EN EL FACEBOOK

1 João Arlindo dos Santos Neto, Oswaldo Francisco de Almeida Júnior Universidade Estadual Paulista

\section{Correspondência}

1João Arlindo dos Santos Neto Universidade Estadual Paulista São Paulo, SP

Email: santosneto@uel.br ORCID: http://orcid.org/0000-0003-1833911X

Submetido em: 31-01-2017

Aceito em: 19-03-2017

Publicado: 17-04-2017

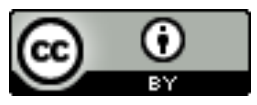

JITA: DD. Academic libraries.

\begin{tabular}{c|c|c|c|c|c}
\hline (C) RDBCI: Rev. Digit. Bibliotecon. Cienc. Inf. & Campinas, SP & v.15 & n.2 & p. 442-468 & maio/ago. 2017 \\
\hline
\end{tabular}


RESUMO: Apresenta uma pesquisa sobre as bibliotecas universitárias e as formas de mediação da informação através das ferramentas web, em especial das redes sociais. Como objetivo identifica e analisa a mediação da informação no Facebook. Quanto aos procedimentos metodológicos, o artigo é de caráter exploratório e utiliza inicialmente de uma breve revisão bibliográfica dos termos biblioteca universitária, redes sociais e mediação da informação e, posteriormente, analisa uma coleta de dados a partir do método da pesquisa documental. Utiliza como técnica de coleta a observação e de análise dos dados a Análise de Conteúdo. Como resultados, apresenta o número e os nomes das contas localizadas na rede social, as características delas (tipo de perfil, número de amigos ou curtidas), quantidade de posts feitos por cada conta e sua periodicidade, o conteúdo das postagens distribuído em 15 categorias temáticas, a interação existente entre as contas das bibliotecas e seus interlocutores, a partir das curtidas, comentários e compartilhamentos. Considera que o uso das redes sociais ainda é pequeno pelas unidades de informação pesquisadas, visto que somente $31 \%$ delas utilizam o Facebook como forma de mediar a informação e interagir com seu público. Conclui que o número de amigos no perfil, curtidas na página ou quantidade de postagens, não garantem uma boa interlocução entre a conta e os usuários, visto que o momento em que os usuários se encontram online na rede interfere mais do que os demais elementos apontados.

PALAVRAS-ChAVE: Biblioteca universitária. Redes sociais. Facebook. Mediação da informação.

ABSTRACT: Presents a research on university libraries and forms of information mediation through web tools, especially social medias. As goal, identify and analyze the mediation of information on Facebook. As for the methodological procedures, the article is exploratory and initially uses a brief bibliographic review of the terms university library, social medias and mediation of information and, later, analyzes a collection of data from the method of documentary research. It uses as technique for data collection the observation and as analysis of the data the Content Analysis. As results, it shows the number and names of the accounts located in the social media, the characteristics of them (type of profile, number of friends or likes), number of posts made by each account and their periodicity, the content of the posts distributed in 15 themed categories, the interaction between the libraries accounts and their interlocutors, from the likings, comments and shares. It considers that the use of social medias by the units of information researched is still small, since only $31 \%$ of them use Facebook as a way to mediate the information and to interact with its public. It concludes that the number of friends in the profile, likes on the page or number of posts do not guarantee a good interlocution between the account and the users, since the moment that the users are online on the network interferes more than the other elements pointed out.

KEYWORDS: University Library. Social medias. Facebook. Mediation of information.

RESUMEN: Presenta una investigación acerca de las bibliotecas universitarias y las formas de mediación de la información por medio de las herramientas web, en especial de las redes sociales. Como objetivo, identifica y analiza la mediación de la información en el Facebook. Cuanto a los procedimientos metodológicos el artículo es de carácter exploratorio y utiliza inicialmente una breve revisión bibliográfica de los términos, biblioteca universitaria, redes sociales y mediación de la información; posteriormente, analiza una colecta de datos a partir del método de la investigación documental. Utiliza como técnica de colecta, la observación, y de análisis de los datos, el Análisis de Contenido. Como resultado, presenta el número y los nombres de los perfiles localizados en la red social, las características de ellas (clase de perfil, número de amigos o 'me gusta'), cantidad de publicaciones hechas por cada cuenta (perfil) y su periodicidad; el contenido de las publicaciones distribuidos en quince (15) categorías temáticas, la interacción existente entre las cuentas/perfiles de las bibliotecas y sus interlocutores, a partir de los 'me gusta', comentarios y las comparticiones. Considera que el uso de las redes sociales todavía es pequeño por las unidades de información investigadas, teniendo en vista que solamente un treinta y uno por ciento (31\%) de ellas utilizan el Facebook como forma de mediar la información e interaccionar con su público. Concluye que el número de amigos en el perfil, 'me gusta' en la página, o cantidad de publicaciones, no garantizan una buena interlocución entre la cuenta y los usuarios, visto que el momento en que los usuarios se encuentran en la red interfiere más que los demás elementos apuntados.

PAlabras ClavE: Biblioteca universitaria. Redes sociales. Facebook. Mediación de la información.

\begin{tabular}{l|l|l|l|l|l}
\hline (C) RDBCI: Rev. Digit. Bibliotecon. Cienc. Inf. & Campinas, SP & v.15 & n.2 & p. $442-468$ & maio/ago. 2017 \\
\hline
\end{tabular}




\section{INTRODUÇÃ̃o}

Devido ao avanço das tecnologias de informação e comunicação (TIC) tornou-se cada vez mais intensa a utilização da web como ferramenta no mundo do trabalho e, também, nos espaços informacionais. Com isso, os profissionais que atuam nesses ambientes procuram se aproximar mais de seus clientes e consumidores. Essa possibilidade de interlocução, entre quem produz/oferece serviços e quem os consome/utiliza, faz com que a interação entre esses sujeitos seja maior. Dependendo do público a ser alcançado, a melhor estratégia para se promover um produto é colocá-lo numa rede social. Dessa forma, os consumidores ficam sabendo mais rapidamente o que é ofertado e quais são os benefícios existentes do que está sendo promovido.

Pensando nas unidades de informação, é hoje mais necessário que elas estejam próximas aos seus usuários e, tendo como foco a biblioteca universitária, infere-se que o seu público alvo é a comunidade que a frequenta, isto é, os alunos, funcionários e professores. Desse modo, acredita-se que a utilização das ferramentas web, em especial das redes sociais pelas bibliotecas universitárias para mediar a informação, seja uma das formas de se aproximar da sua comunidade e, ainda mais, fazer com que os seus usuários potenciais venham a se tornar usuários reais (CALIL JUNIOR; ALMENDRA, 2016).

A discussão existente a respeito das ferramentas web causarem o fim das bibliotecas e dos mediadores, nos parece ser precipitada, “[...] a apreensão esperançosa da internet como fim da mediação era, na realidade, a descoberta de um potencial de liberdade resultante da crise do mediador do interesse geral próprio da modernidade." (VAZ, 2006, p. 47). A web amplia os leques de possibilidade para a promoção de produtos e serviços que visam mediar a informação, almejando atender as necessidades e interesses da sociedade. Mediar a informação é um dos principais objetivos da biblioteca universitária, este fazer está presente em todas as atividades dos profissionais da informação. Ele ocorre no serviço de referência, no balcão de empréstimo, nas atividades culturais, no processamento técnico (SANTOS NETO, 2014) e, pode também, se dar nas redes sociais.

A justificativa para o desenvolvimento deste artigo pauta-se, também, no discurso de Gomes e Santos (2011, p. 831) quando as autoras reconhecem a necessidade de "[...] realização de pesquisas que identifiquem e analisem as possibilidades de se intensificar o uso de recursos de comunicação na web, visando a ampliação das atividades de mediação da informação." Algumas pesquisas nessa linha de estudo foram desenvolvidas, com maior ênfase em bibliotecas públicas e um pouco menor em bibliotecas universitárias. Ao longo do texto, elas são comentadas e discutidas visando à fundamentação para realização desta e comparação dos resultados obtidos nesta e por outras investigações.

Sendo assim, o que atraiu fortemente o foco deste estudo foram os processos e práticas informacionais - cujas ações não se restringem ao fazer implícito ou explícito, nem à

\begin{tabular}{l|l|l|l|l|l}
\hline (C) RDBCI: Rev. Digit. Bibliotecon. Cienc. Inf. & Campinas, SP & v.15 & n.2 & p. 442-468 & maio/ago. 2017 \\
\hline
\end{tabular}


possibilidade de neutralidade no fazer do bibliotecário - que ultrapassam a "barreira" entre serviços do processamento técnico ou do serviço de informação e referência, tornando-se atividades imprescindíveis e de alto valor contributivo para os serviços de modo geral de uma biblioteca.

Evidencia-se a necessidade de reconhecer a interferência da mediação, objetivando contribuir para a compreensão dos fazeres biblioteconômicos para que sejam conhecidos, discutidos, visando a um autêntico fazer profissional e social, pautado em uma prática transformadora colaborativa.

Mediação da informação no Facebook é o centro da discussão do presente artigo, que teve como objetivo verificar se as bibliotecas universitárias o têm utilizado ou não, para mediar a informação e como essa prática tem sido desempenhada. A seguir são apresentados alguns conceitos que buscam estabelecer uma relação entre as bibliotecas universitárias e o uso do Facebook no processo da mediacional.

\section{BIBLIOTECAS UNIVERSITÁRIAS E O USO DO FACEBOOK NA MEDIAÇÃO DA INFORMAÇÃO}

As bibliotecas universitárias buscam atuar como órgãos dinâmicos, seja por natureza ou por necessidade. O desafio delas é se reinventar a todo o momento, primeiro porque as informações são produzidas e compartilhadas de maneira muito rápida, e segundo porque para alguns usuários a tecnologia tem impulsionado cada vez mais a uma menor procura pelas bibliotecas "físicas". O avanço das ferramentas web fez com que os leitores e usuários passassem a ter informação de modo geral, de suas próprias residências e, atualmente, utilizam para esse acesso os seus dispositivos móveis, através de uma conexão de rede.

Cabe, então, a essa unidade manter-se atualizada e preparada. Acredita-se que uma forma de se buscar isto, seja se inserindo nas redes sociais. No entanto, se faz necessário que as bibliotecas universitárias criem um ambiente que proporcione leitura, discussões, apropriação da informação, bem como produção e compartilhamento de conhecimento construído. De acordo com Gomes e Santos (2011, p. 845):

[...] a biblioteca universitária deve explorar mais intensamente os recursos da web social, contribuindo assim com a formação de redes sociais no seu ambiente físico e/ou virtual, desenvolvendo uma interação mais intensa entre bibliotecários e usuários, como também entre os próprios usuários, garantindo a troca de informações, o debate, e facilitando a apropriação da informação.

As atividades e funções a serem desempenhadas pelas bibliotecas universitárias e a sua prestação de produtos e serviços foram sendo aperfeiçoadas e customizadas ao longo dos anos, levando-se em conta diferentes necessidades informacionais e distintos momentos, porém, a sua missão permaneceu a mesma, isto é, mediar a informação.

No cenário atual é imprescindível que as bibliotecas universitárias procurem por novas competências demandadas pela sociedade da informação, da comunicação e do conhecimento.

\begin{tabular}{l|l|l|l|l|l}
\hline (C) RDBCI: Rev. Digit. Bibliotecon. Cienc. Inf. & Campinas, SP & v.15 & n.2 & p. $442-468$ & maio/ago. 2017 \\
\hline
\end{tabular}


É preciso que essas unidades se lembrem, a todo o momento, de que a satisfação do usuário é o objetivo do seu fazer e, para isso Santos Neto (2014, p. 25), alerta que elas "[...] se atentem às políticas que foram estipuladas para se almejar essa satisfação, à melhoria e inovação de seus serviços, bem como contribuir no resultado da formação acadêmica e profissional de seus alunos."

A partir do momento que as bibliotecas universitárias se adequarem às mudanças, é provável que elas aumentem o seu "alcance", que antes era limitado ao usuário local e há alguns anos atinge usuários virtuais e potenciais. A criação de redes sociais online pelas bibliotecas não só faz com que ocorra a interlocução entre bibliotecários e usuários, mas permite o compartilhamento de recursos informacionais em um ambiente eletrônico, onde os usuários podem criar vínculo com a unidade de informação e descobrir se os interesses e necessidades de outros usuários são comuns aos seus, a partir do que é visualizado, comentado, curtido (MANESS, 2007) e compartilhado.

Para Tomaél (2007) "Uma rede social refere-se a um conjunto de pessoas (ou organizações ou outras entidades) conectadas por relacionamentos sociais, motivadas pela amizade, relações de trabalho ou troca de informação." Como os usuários de bibliotecas, possuem necessidades informacionais e interesses de uma mesma natureza, que é informacional, constituem, portanto, uma rede social. Sendo assim, o profissional da informação que visa satisfazer essas necessidades, precisa inserir-se nesta rede.

As redes sociais podem ser formadas por pessoas ou organizações que possuem um objetivo e/ou interesse em comum, os laços são estabelecidos a partir da identidade e do perfil de cada usuário. Elas “[...] constituem uma das estratégias subjacentes utilizadas pela sociedade para o compartilhamento da informação e do conhecimento, mediante as relações entre atores que as integram." (TOMAÉL; ALCARÁ; DI CHIARA, 2005, p. 93). Uma das maiores características das redes sociais é o compartilhamento de informação, isto é, a possibilidade de divulgar rapidamente algo produzido por terceiros ou pelo próprio usuário.

A ideia do visionário Paul Otlet, que buscava disponibilizar o conhecimento para o mundo em busca da paz mundial, pode ser comparada, metaforicamente, à capacidade que o Facebook apresenta a quem faz seu uso, os usuários, exceto pela paz mundial. Eles são mais de "[...] quinhentos milhões de usuários [que] recebem cerca de trinta bilhões de recomendações de links, notícias, posts, notas, fotos a cada mês [...]" (SANTARÉM SEGUNDO, 2011, p. 102).

Em concordância com pensamento a seguir, acredita-se que "As redes que constituem espaços em que o compartilhamento da informação e do conhecimento é proficiente e natural são espaços também de aprendizagem e, assim, tornam-se um ambiente para o desenvolvimento e para a inovação." (TOMAEL; ALCARÁ; DI CHIARA, 2005, p. 102). Ainda que o Facebook não seja uma rede tão recente, pois existe há mais de 12 anos, constituise como um caminho para inovar a prestação dos serviços e produtos oferecidos pelas organizações.

O Facebook é uma rede social de relacionamento online gratuita e para utilizá-la é necessário realizar um cadastro, a partir de uma conta de e-mail. Após criá-lo é possível manter um perfil pessoal, seguir e/ou criar uma página, adicionar e se comunicar com outros usuários,

\begin{tabular}{l|l|l|l|l|l}
\hline (C) RDBCI: Rev. Digit. Bibliotecon. Cienc. Inf. & Campinas, SP & v.15 & n.2 & p. $442-468$ & maio/ago. 2017 \\
\hline
\end{tabular}


criar eventos, postar conteúdo próprio no campo "No que você está pensando?" ou compartilhar um já existente, entre outras tarefas (FACEBOOK, 2016a). Lançado em 2004, tornou-se em poucos anos a rede social mais utilizada em todo o mundo, sendo que em 2012 alcançou o total de um bilhão de usuários ativos e superou o uso de outras grandes redes como o MySpace e o Twitter, com mais de um bilhão de acessos mensais (KAZENIAC, 2009). Os dados evidenciam a extensão do alcance das bibliotecas que estiverem inseridas nesse ambiente. Para Bernardino, Suaiden e Cuevas-Cerveró (2014, p. 121) o uso das redes sociais pelas bibliotecas públicas "[...] é uma excelente ferramenta para a circulação e disseminação da informação.", acrescenta-se a este pensamento que também é para as bibliotecárias universitárias, e que ambas não só poderiam se comunicar com seus usuários, como também mediar informação e conhecimento.

Visto que o Facebook apresenta uma adesão cada vez maior da população mundial, as organizações adentraram também neste espaço, seja para promover sua marca, divulgar produtos e serviços, ou simplesmente, se relacionar com seus clientes. De acordo com Galvão (2016) "Ter uma fan page do seu projeto ou empresa no Facebook é quase tão importante quanto ter um blog ou site [...]". Já que entre os fazeres dos bibliotecários, está a busca pela satisfação das necessidades informacionais de seus usuários e, também, a procura por uma interlocução ética entre eles, estar inserido nas redes sociais de relacionamento, em especial no Facebook, é uma estratégia para se alcançar isto. Aproxima-se a este pensamento, o discurso de Amaral e Guimarães (2008) ao afirmarem que "O relacionamento que a unidade de informação deseja manter com seus públicos será o reflexo do processo de comunicação utilizado no ambiente físico da prestação de serviços da unidade de informação ou no seu website $[\ldots] "$.

Ao reconhecer o Facebook como espaço para mediação da informação, é possível que os profissionais da informação interajam mais facilmente com os usuários e mantenham um relacionamento contínuo e, até mesmo, duradouro com eles. A maioria dos usuários das bibliotecas universitárias possui uma conta na referida rede e está familiarizada com a dinâmica que os conteúdos são postados nela, o que não seria para eles uma novidade em relação a isso, mas sim quanto ao publicador das postagens, no caso as bibliotecas universitárias por meio de seus mediadores.

A inserção das bibliotecas nas redes sociais as evidencia como dispositivo informacional e mostra como elas se preocupam em interagir com seus usuários, pois estar presente no mesmo ambiente em que seu público está é um sinal de interesse e atenção. Gomes (2014, p. 53) acrescenta ainda que a mediação é "[...] uma ação relacionada ao cuidado e aos aspectos psicológicos, estéticos e éticos que envolvem esse processo fundamental no trabalho com a informação."

O termo mediação da informação tem sido bastante discutido e utilizado nas pesquisas da Ciência da Informação (CI). No Brasil, o aumento no interesse em trabalhar com o conceito e suas implicações têm feito com o que o número de publicações com a temática na área aumente (SANTOS NETO, 2014).

Alguns autores como Signates (1998) afirmam que o número de citações do termo mediação seja suficiente para a compreensão de seu entendimento e importância para a área da Comunicação e também para a CI. No entanto, percebe-se que o termo ainda não é claro para

\begin{tabular}{l|l|l|l|l|l}
\hline (C) RDBCI: Rev. Digit. Bibliotecon. Cienc. Inf. & Campinas, SP & v.15 & n.2 & p. 442-468 & maio/ago. 2017 \\
\hline
\end{tabular}


todos os profissionais e que não há consenso sobre ele.

A mediação é uma ação de interposição de um "terceiro", este sempre exerce, negocia e acompanha durante o processo mediativo (DAVALLON, 2007; MARTELETO, 2009). Inferese que o ato de mediar ou a mediação necessita de um agente mediador, denominado pelos referidos autores como "terceiro", que facilite, interfira e medeie algo ou alguma coisa para alguém.

Davallon (2007, p. 10) defende que a mediação "[...] aparece cada vez que há necessidade de descrever uma acção implicando uma transformação da situação ou do dispositivo comunicacional, e não uma simples interacção entre elementos já constituídos [...]”. Outra definição que complementa a anteriormente citada, é a de Araújo (2012), o autor nos sugere que a ideia de mediação consiste em "[...] uma intervenção intencional, de um 'colocarse entre' e, por meio justamente desta ação, fazer se relacionarem diferentes sujeitos, instituições e instâncias." Compreende, portanto, que a mediação é intencional, não é neutra e nem passiva, permite que ocorra relações pessoais ou institucionais. Em complemento ao referido pensamento, vislumbra-se também que a mediação ocorre, muitas vezes, de maneira inconsciente e não planejada.

Após discutir de maneira introdutória o termo "mediação" e a ideia da qual se apropriou nos parágrafos anteriores, optou-se por discutir a reformulada definição, proposta por Almeida Júnior (2015, p. 25, grifo nosso) ao dizer que a mediação da informação:

\section{[...] é toda ação de interferência - realizada em um processo, por um profissional da informação e na ambiência de equipamentos informacionais -, direta ou indireta; consciente ou inconsciente; singular ou plural, individual ou coletiva; visando a apropriação de informação que satisfaça, parcialmente e de maneira momentânea, uma necessidade informacional, gerando conflitos e novas necessidades informacionais.}

Desse conceito podem-se destacar quatro elementos: interferência, processo, apropriação e conflito. Vislumbra-se a interferência nesse contexto como uma ação planejada ou espontânea dos profissionais que almejam colaborar com diferentes sujeitos em um equipamento informacional na busca de informação. Deste modo, a mediação só ocorre em um processo contínuo, que objetiva despertar, nos usuários, novas necessidades (SANTOS NETO; BORTOLIN, 2016). Relaciona-se a este processo, a dialogia apresentada por Gomes (2014), quando distintos sujeitos estão envoltos na mediação, compartilham informação e constroem significações.

Quanto à apropriação, ela se dá no instante em que o usuário atribui significado(s) à informação, portanto é um ato pessoal e singular; variando de sujeito para sujeito. Além da maneira que a informação será apropriada por cada indivíduo ser diferente, ela pode se transformar no decorrer da existência do mesmo, visto que "[...] o homem é um ser inacabado, é um ser por se fazer, assim, o conhecimento e a informação também são inacabados." (ALMEIDA JÚNIOR, 2015, p. 21).

\begin{tabular}{c|c|c|c|c|c}
\hline (C) RDBCI: Rev. Digit. Bibliotecon. Cienc. Inf. & Campinas, SP & v.15 & n.2 & p. 442-468 & maio/ago. 2017 \\
\hline
\end{tabular}


Por fim, o conflito que está no cerne da mediação, uma vez que se compreende a informação não somente como uma forma de solução de problemas, mas ao contrário, como geradora de dúvidas levando o indivíduo a construir seus saberes, em um movimento pendular com ideias consonantes e dissonantes (SANTOS NETO; BORTOLIN, 2016).

As ações mediativas devem ser realizadas intencionalmente, pensadas com um objetivo a ser alcançado, visto que os bibliotecários afirmam em seu discurso que o foco do seu trabalho são os usuários (SANTOS NETO, 2014). Deste modo, pensando no uso das redes sociais para mediar a informação, Costa e Almeida Júnior (2012, p. 66) sugerem que "[...] não devemos fazer uso das tecnologias sem levar em consideração o que for ao encontro dos interesses dos usuários [...]". O conteúdo a ser postado nas redes sociais da biblioteca deve atender às necessidades dos usuários, de forma que eles possam sanar, mesmo que momentaneamente, sua necessidade informacional.

Em seguida, apresenta-se a metodologia utilizada para a realização do presente artigo que objetivou investigar o uso do Facebook pelas bibliotecas universitárias das Instituições Estaduais de Ensino Superior (IEES) do Paraná, quando atuam no intuito de mediar a informação. Como objetivos específicos buscou-se identificar e caracterizar as contas, mensurar a quantidade de posts feitos por cada uma e a periodicidade deles, categorizar e analisar o conteúdo expresso nas postagens e observar a interlocução existente entre as contas e seus usuários, a partir de indicadores da própria plataforma, como o número de curtidas, comentários e compartilhamentos.

\section{PROCEDIMENTOS METOdOLÓGICOS}

A investigação para este texto foi realizada a partir de uma breve revisão bibliográfica a respeito das bibliotecas universitárias e o uso do Facebook na mediação da informação. Também se empregou a pesquisa documental, em que a fonte dos dados é o documento (histórico, institucional, associativo, oficial) (TOZONI-REIS, 2010). Os documentos utilizados para a investigação foram os próprios sites das IEES e suas contas do Facebook. A escolha por esta rede se deu pelo seu alcance e popularidade, sendo a rede social mais acessada no início do século XXI (SANTARÉM SEGUNDO, 2011).

Como técnica de coleta de dados para a pesquisa documental, utilizou-se da observação, que segundo Marconi e Lakatos (2011) pode ser estruturada e "controlada". No entanto, ela não deve ser muito rígida, pois o pesquisador poderá lidar com situações não planejadas anteriormente, além da tentativa de buscar sua imparcialidade na execução e análise dos dados, mesmo que dificilmente ela seja alcançada. Para a coleta de dados utilizou-se de um roteiro predefinido que buscou: caracterizar as contas (tipo de perfil, número de amigos ou curtidas); quantidade de posts realizados por cada conta; a periodicidade com que eram feitos; analisar o conteúdo das postagens a partir de categorias temática; observar a interação existente entre as

\begin{tabular}{l|l|l|l|l|l|l}
\hline (C) RDBCI: Rev. Digit. Bibliotecon. Cienc. Inf. & Campinas, SP & v.15 & n.2 & p. 442-468 & maio/ago. 2017 \\
\hline
\end{tabular}


contas das bibliotecas e seus usuários (atendo-se às curtidas, comentários e compartilhamentos).

A análise dos dados se deu através da categorização temática das postagens a partir da técnica de análise de conteúdo. Segundo Bardin (2004, p. 33) esta técnica refere-se a "[...] um conjunto de técnicas de análise das comunicações, que utiliza procedimentos sistemáticos e objetivos de descrição do conteúdo das mensagens." A autora defende que a análise de conteúdo se fundamenta em codificar, categorizar um segmento do texto para entender o seu sentido. Sabendo-se que a técnica utiliza procedimentos sistemáticos, é imprescindível que haja uma categorização dos dados, para que se possa aferir mais facilmente a denotação das informações. As categorias foram atribuídas posteriormente à coleta, visto que ao estabelecêlas previamente, poderiam limitar a interpretação e discussão.

Posteriormente, acompanhou-se os posts das contas cadastradas no período de maio a outubro de 2016, ou seja, durante 6 meses. Observou-se as postagens tendo como norte um instrumento de coleta de dados, neste caso o roteiro preestabelecido, que identificou o número e os nomes das contas localizadas no Facebook, as características delas (tipo de perfil, número de amigos ou curtidas), quantidade de posts feitos por cada conta e sua periodicidade, o conteúdo das postagens, a interação existente entre as contas das bibliotecas e seus interlocutores, a partir das curtidas, comentários e compartilhamentos.

A abordagem utilizada para tal análise, se deu de maneira qualiquantitativa, pois além de por meio da observação, coletar indicadores das formas de mediação da informação pelas bibliotecas universitárias, enfatizou-se também nos indicadores numéricos e porcentuais sobre o fenômeno pesquisado, com o uso de gráficos, quadros e tabelas, conforme é apresentado a seguir, na seção de resultados e discussão do presente artigo.

\section{RESULTADOS E DISCUSSÃo}

O corpus da pesquisa documental são os sites das bibliotecas universitárias das IEES do Paraná e suas homepages do Facebook. No quadro a seguir é possível visualizar o número de bibliotecas e a sua localização por Cidade/Campus do Estado. 
Quadro 1. Relação das bibliotecas universitárias nas IES estaduais do Paraná

\begin{tabular}{|c|c|c|c|}
\hline IEES & CIDADE/CAMPUS & BIBLIOTECAS & TOTAL \\
\hline UEL & Londrina & $\begin{array}{c}\text { - Central } \\
\text { - Setorial/CCS } \\
\text { - Setorial/CH } \\
\text { - Setorial/COU } \\
\text { - Setorial/EAAJ }\end{array}$ & 5 \\
\hline \multirow{8}{*}{ UEM } & Maringá & $\begin{array}{c}\text { - Central } \\
\text { - Setorial do Colégio de Aplicação } \\
\text { Pedagógica/UEM } \\
\text { - Setorial do Nupélia } \\
\text { - Setorial do PPD } \\
\text { - Setorial Hospital Universitário } \\
\text { - Setorial MAT }\end{array}$ & \multirow{8}{*}{13} \\
\hline & Cianorte & - Extensão de Cianorte/Tecidoteca & \\
\hline & Cidade Gaúcha & - Extensão de Cidade Gaúcha & \\
\hline & Goioerê & - Extensão do Goioerê & \\
\hline & Diamante do Norte & - Central & \\
\hline & Umuarama & $\begin{array}{l}\text { - Extensão do CCA-Fazenda } \\
\text { - Extensão do CTC }\end{array}$ & \\
\hline & Ivaiporã & - Central & \\
\hline & \multicolumn{2}{|r|}{ Iguatemi; Porto Rico* } & \\
\hline \multirow{3}{*}{ UENP } & Bandeirantes & - Campus Luiz Meneghel & \multirow{3}{*}{6} \\
\hline & Cornélio Procópio & $\begin{array}{c}\text { - Campus Cornélio } \\
\text { - Campus Cornélio Centro }\end{array}$ & \\
\hline & Jacarezinho & $\begin{array}{c}\text { - Setorial do CCS } \\
\text { - Setorial do CCHE-CLCA/CJ } \\
\text { - Setorial do CCSA }\end{array}$ & \\
\hline \multirow[t]{2}{*}{ UEPG } & Ponta Grossa & $\begin{array}{l}\text { - Central Professor Faris Michaele } \\
\text { - Campus Uvaranas } \\
\text { - Colégio Agrícola Augusto Ribas }\end{array}$ & \multirow[t]{2}{*}{3} \\
\hline & \multicolumn{2}{|c|}{$\begin{array}{c}\text { Castro, Jaguariaíva, Palmeira, São Mateus do Sul, } \\
\text { Telêmaco Borba* }\end{array}$} & \\
\hline \multirow{6}{*}{ UNESPAR } & Apucarana & - FECEA & \multirow{6}{*}{7} \\
\hline & Campo Mourão & - Fecilcam & \\
\hline & Curitiba & $\begin{array}{c}\text { - EMBAP } \\
\text { - Octacílio de Souza Braga/FAP }\end{array}$ & \\
\hline & Paranaguá & - Central & \\
\hline & Paranavaí & - Fapipa & \\
\hline & União da Vitória & - Dante de Jesus Augusto/Fafiuv & \\
\hline \multirow{3}{*}{ UNICENTRO } & Guarapuava & $\begin{array}{l}\text { - Cedeteg } \\
\text { - Santa Cruz } \\
\end{array}$ & \multirow{3}{*}{3} \\
\hline & Irati & $\begin{array}{l}\text { - Centro de Doc. e Memória da } \\
\text { Unicentro } \\
\end{array}$ & \\
\hline & Chopinzinho; Coro & $\begin{array}{l}\text { Vivida; Laranjeiras do Sul; Pitanga; } \\
\text { rudentópolis* }\end{array}$ & \\
\hline
\end{tabular}




\begin{tabular}{|c|c|c|c|}
\hline \multirow{4}{*}{ UNIOESTE } & Cascavel & - Central da Unioeste & \multirow{3}{*}{5} \\
\cline { 2 - 3 } & Foz do Iguaçu & - Central \\
\cline { 2 - 3 } & Toledo & - Central & \\
\cline { 2 - 3 } & Francisco Beltrão & - Central \\
\cline { 2 - 3 } & $\begin{array}{c}\text { Marechal Cândido } \\
\text { Rondon }\end{array}$ & - Central & $\mathbf{4 2}$ \\
\hline
\end{tabular}

Fonte: Dados da pesquisa (2016).

* Cidades que não apresentam identificação de bibliotecas nos seus sites.

Segundo o quadro 1, no Estado do Paraná são sete IEES distribuídas em 37 cidades/campus pelo Estado e agregam 42 bibliotecas universitárias. Ao localizar o site de cada biblioteca, foi verificada a indicação do contato do Facebook representado por um ícone da rede social ou nome da conta. Esta primeira etapa foi pouco produtiva, visto que somente algumas fazem menção à rede no site institucional. A segunda estratégia foi pesquisar diretamente na referida rede social. A pesquisa foi realizada na barra comum de busca do Facebook, digitando de forma aleatória e com diferentes combinações o nome da instituição, nome da faculdade, nome do campus e o termo biblioteca. Exemplo: Biblioteca da UEL; Biblioteca Unioeste; Cianorte Biblioteca UEM etc.

Ao pesquisar no Facebook as contas das bibliotecas universitárias identificadas no quadro 1, encontrou-se 13 cadastros na rede social. O nome na rede, o link de acesso, o tipo da conta a que se referem e a vinculação institucional, respectivamente, são indicados no quadro a seguir.

Quadro 2. Facebook das bibliotecas universitárias estaduais do Paraná

\begin{tabular}{|c|c|c|c|}
\hline $\mathbf{N}^{\mathbf{o}}$ & NOME E LINK DE ACESSO NO FACEBOOK & $\begin{array}{l}\text { TIPO DA } \\
\text { CONTA }\end{array}$ & IEES \\
\hline B1 & $\begin{array}{l}\text { Bibliotecas UEL } \\
\text { https://www.facebook.com/bibliotecauel/?ref=page_intern } \\
\text { al }\end{array}$ & Locais & \multirow[t]{2}{*}{ UEL } \\
\hline B2 & $\begin{array}{l}\text { Uel Bibliotecas } \\
\text { https://www.facebook.com/bibliotecas.uel }\end{array}$ & Pessoas & \\
\hline B3 & $\begin{array}{l}\text { Biblioteca Central Uem } \\
\text { https://www.facebook.com/Bceuem }\end{array}$ & Pessoas & \multirow{5}{*}{ UEM } \\
\hline B4 & $\begin{array}{l}\text { Biblioteca Crc Uem } \\
\text { https://www.facebook.com/biblioteca.crcuem?fref=ts }\end{array}$ & Pessoas & \\
\hline B5 & $\begin{array}{l}\text { Biblioteca do Cap Uem } \\
\text { https://www.facebook.com/Biblioteca-do-Cap-Uem- } \\
\underline{250767338447211 / ? \text { fref=ts }}\end{array}$ & Páginas & \\
\hline B6 & $\begin{array}{l}\text { Biblioteca Setorial - Anos iniciais do Cap/Uem } \\
\text { https://www.facebook.com/bibliotecaanosiniciaiscap2015 } \\
\underline{I}\end{array}$ & Páginas & \\
\hline B7 & $\begin{array}{l}\text { Tecidoteca - Moda UEM } \\
\text { https://www.facebook.com/tecidotecauem/?fref=ts }\end{array}$ & Páginas & \\
\hline
\end{tabular}

\begin{tabular}{l|l|l|l|l|l}
\hline (C) RDBCI: Rev. Digit. Bibliotecon. Cienc. Inf. & Campinas, SP & v.15 & n.2 & p. 442-468 & maio/ago. 2017 \\
\hline
\end{tabular} 


\begin{tabular}{|c|l|l|c|}
\hline B8 & $\begin{array}{l}\text { Biblioteca Uenp Cche-Clca } \\
\text { https://www.facebook.com/profile.php?id=100013093540 } \\
\text { 251\&fref=ts }\end{array}$ & Pessoas & UENP \\
\hline B9 & $\begin{array}{l}\text { BICEN } \\
\text { https://www.facebook.com/uepgbicen/?fref=ts }\end{array}$ & Locais & UEPG \\
\hline B10 & $\begin{array}{l}\text { Biblioteca Unespar Campus Li - Curitiba/fap } \\
\text { https://www.facebook.com/Biblioteca-Unespar-Campus- } \\
\text { li-Curitibafap-554880591369831/ }\end{array}$ & Páginas & UNESPAR \\
\hline B11 & $\begin{array}{l}\text { Biblioteca Unicentro Cedeteg } \\
\text { https://www.facebook.com/biblioteca.cedeteg?fref=ts }\end{array}$ & Pessoas & $\begin{array}{l}\text { UNICENT } \\
\text { RO }\end{array}$ \\
\hline B12 & $\begin{array}{l}\text { Biblioteca Cascavel Unioeste } \\
\text { https://www.facebook.com/bibliotecacascavel }\end{array}$ & Pessoas \\
\hline B13 & $\begin{array}{l}\text { Biblioteca Unioeste Toledo } \\
\text { https://www.facebook.com/bibliotecaunioeste.toledo.5?fr } \\
\text { ef=ts }\end{array}$ & Pessoas & UNIOESTE \\
\hline
\end{tabular}

Fonte: Dados da pesquisa (2016).

Do total de 42 bibliotecas, 13 possuem conta cadastrada na rede social analisada, isto é, aproximadamente $31 \%$ estão atentas para novas formas de se relacionar com seus usuários. Bernardino, Suaiden e Cuevas-Cerveró (2014) constataram que somente 18\% das bibliotecas públicas do Estado do Ceará usam o Facebook.

Em pesquisa realizada por Gomes e Santos (2009), as autoras constataram que é baixo o uso da internet pelas bibliotecas universitárias para mediar a informação e que ele deveria ser mais explorado. Em complemento, Novelli, Hoffman e Gracioso (2011, p. 159) afirmam que os "[...] recursos interativos 2.0 ainda são pouco utilizados no Brasil, e fatores tecnológicos, humanos e sociais estão atrelados a isto."

Ressalta-se que algumas bibliotecas possuem registro "Locais" cadastrada, pois o Facebook as identifica automaticamente, devido à localização geográfica para a realização de check-ins no espaço frequentado. No entanto, essas contas não apresentam curtidas, interações ou gerenciamento por alguma biblioteca, somente aparecem na busca, portanto, foram desconsiderados para esta análise.

Como é possível analisar a partir dos dados obtidos, as categorias das contas das bibliotecas universitárias que possuem cadastro no Facebook variam entre: locais ${ }^{1}$, pessoas ${ }^{2} \mathrm{e}$ páginas ${ }^{3}$. Dos 13 cadastros, sete são "Pessoas", três "Locais" e três "Páginas". Os perfis do tipo

\footnotetext{
${ }^{1}$ As páginas de locais são aquelas que os usuários podem fazer check-in e comentar sobre o lugar onde estão. O administrador da página também pode postar e compartilhar conteúdos em sua linha do tempo.

${ }^{2} \mathrm{O}$ perfil pessoal é um conjunto de fotos, histórias e experiências que contam a sua história. Seu perfil também abrange a sua Linha do Tempo (FACEBOOK, 2016c).

${ }^{3}$ Páginas permitem que empresas, marcas e organizações se conectem com as pessoas no Facebook (FACEBOOK, 2016c).
}

\begin{tabular}{l|l|l|l|l|l}
\hline (C) RDBCI: Rev. Digit. Bibliotecon. Cienc. Inf. & Campinas, SP & v.15 & n.2 & p. 442-468 & maio/ago. 2017 \\
\hline
\end{tabular}


"Pessoas" se caracterizam como aqueles que possuem maior interlocução com os usuários da rede, pois é possível adicionar amigos e conversar no bate papo ou messenger. Neste perfil, costuma-se publicar comentários, fotos, vídeos etc., como também é possível o compartilhamento de postagens feitas por outros usuários.

Os do tipo "Página" são aqueles que recebem curtidas e permitem aos usuários a escolha de serem notificados ou não a cada nova postagem, assim como a opção de seguir ou não a página, fazendo com que os conteúdos por ela postados não apareçam na linha do tempo deles. Este tipo de conta, geralmente mais institucional, visa promover a organização e divulgar seus produtos e serviços. Já aqueles de perfil "Locais", apresentam todos os check-ins realizados ou publicações feitas num determinado lugar, geralmente acompanhados com fotos e comentários sobre ele. Este tipo de conta também pode receber curtidas.

De acordo com o quadro 2, a IEES que apresentou mais contas cadastradas no Facebook é a UEM, com cinco. Com duas contas UEL e UNIOESTE, e com apenas uma as demais IEES. Ao verificar a conexão/alcance que cada perfil ou página possuía no momento da coleta, isto é, o número de amigos ou de curtidas existente, chegou-se aos seguintes resultados, conforme a tabela 1 .

Tabela 1. Quantidade de amigos no perfil ou curtidas na página

\begin{tabular}{lcc}
\hline \multicolumn{1}{c}{ NOME NO FACEBOOK } & 8 & - \\
Bibliotecas UEL & - & $\mathbf{2 . 1 1 5}$ \\
Uel Bibliotecas & 1.35 & - \\
& 3 & \\
Biblioteca Central Uem & 1.08 & - \\
Biblioteca Crc Uem & 6 & \\
Biblioteca do Cap Uem & 447 & - \\
Biblioteca Setorial - Anos iniciais do Cap/Uem & - & 405 \\
Tecidoteca - Moda UEM & - & 73 \\
Biblioteca Uenp Cche-Clca & - & 1.511 \\
BICEN & 569 & - \\
Biblioteca Unespar Campus Li- Curitiba/fap & - & 341 \\
Biblioteca Unicentro Cedeteg & - & 0 \\
& $\mathbf{4 . 9 9}$ & - \\
Biblioteca Cascavel Unioeste & $\mathbf{7}$ & \\
Biblioteca Unioeste Toledo & 771 & - \\
\hline
\end{tabular}

Fonte: Dados da pesquisa (2016).

Dentre os perfis “Pessoas”, o que possui mais amigos na rede é o da Biblioteca Unicentro Cedeteg (4.997). Posteriormente, aparecem os registros: Uel Bibliotecas (1.353), Biblioteca

\begin{tabular}{l|c|c|c|c|c}
\hline (C) RDBCI: Rev. Digit. Bibliotecon. Cienc. Inf. & Campinas, SP & v.15 & n.2 & p. 442-468 & maio/ago. 2017 \\
\hline \multicolumn{6}{c}{ [454] }
\end{tabular}


Central Uem (1.086), Biblioteca Unioeste Toledo (902), Biblioteca Cascavel Unioeste (771), Biblioteca Uenp Cche-Clca (569) e Biblioteca Crc UEM (447).

Quanto àqueles que são "Páginas" e "Locais", a conta que recebeu mais curtidas é a Bibliotecas UEL (2.115), seguida pela Tecidoteca Moda UEM (1.511), Biblioteca Cap UEM (405), BICEN (341) e Biblioteca Setorial - Anos iniciais do Cap UEM (73). A conta da Biblioteca Unespar Campus Li - Curitiba/fap 4 está ativa e é do tipo "Páginas", portanto foi criada por alguém e não foi desconsiderada nesta investigação.

Após caracterizá-las segundo o tipo de conta, pode-se quantificar os posts e chegou-se a um total de 959 postagens. O gráfico a seguir apresenta a distribuição deles entre as contas das bibliotecas indicadas no quadro 2 .

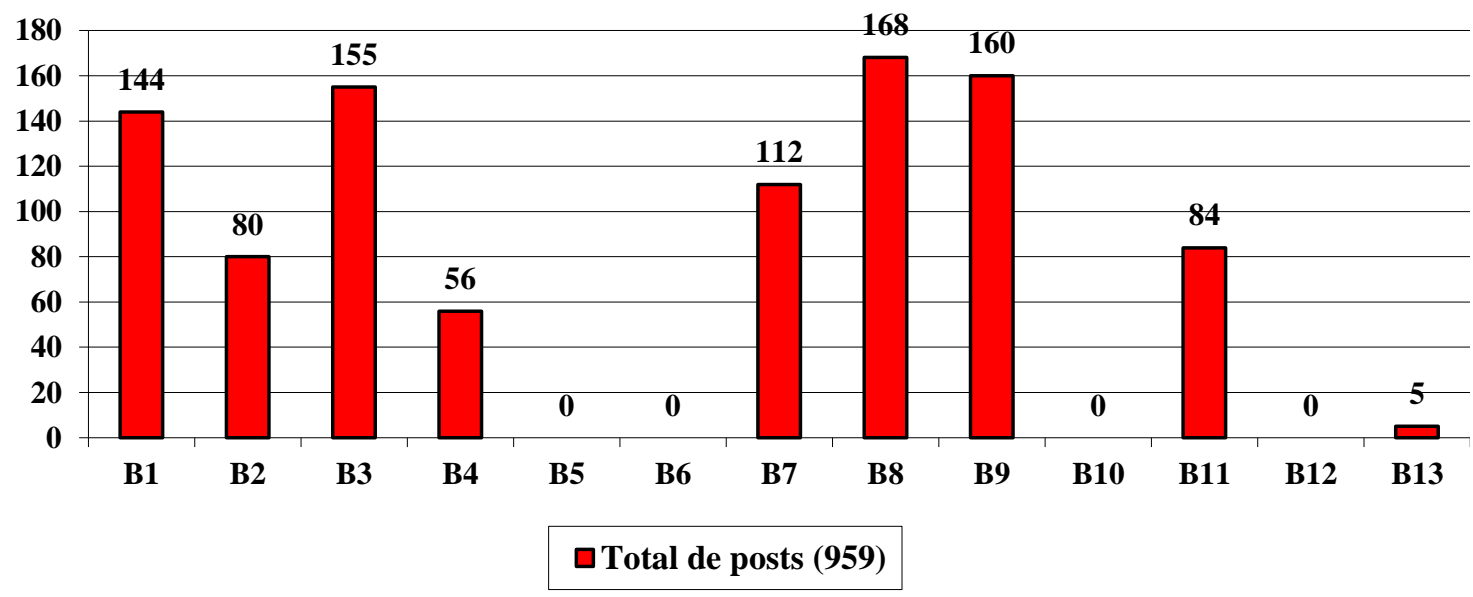

Gráfico 1. Quantidade de posts realizados por cada biblioteca

Fonte: Dados da pesquisa (2016).

Legenda: As bibliotecas são indicadas pela sigla B + o número correspondente conforme quadro 2.

O gráfico 1 mostra a quantidade de postagens que cada biblioteca realizou no período analisado. Os perfis que apresentaram a maior quantidade foram respectivamente a Biblioteca Uenp Cche-Clca (168), BICEN (160), Biblioteca Central Uem (155) e Bibliotecas UEL (144). Em seguida, Tecidoteca - Moda UEM (112), Biblioteca Unicentro Cedeteg (84), Uel Bibliotecas (80), Biblioteca Crc Uem (56) e Biblioteca Unioeste Toledo (5). Ressalta-se que ainda que esta última conta tenha apresentado poucas postagens em seis meses, há uma usuária da rede que trabalha na biblioteca e posta frequentemente em sua timeline ${ }^{5}$ e marca a biblioteca em seus posts, fazendo com que os conteúdos postados apareçam na linha do tempo do perfil da B13, no entanto, eles não foram considerados nesta análise, visto que tais postagens não são originárias da conta da biblioteca. É possível verificar que quatro perfis não apresentaram nenhuma postagem no período analisado, sendo B5, B6, B10 e B12. Este fato representa que

\footnotetext{
${ }^{4}$ A conta ainda não possui curtidas e/ou publicações.

${ }^{5}$ Linha do tempo em português, significa o lugar em que as postagens aparecem no Facebook.
}

\begin{tabular}{l|l|l|l|l|l|l}
\hline (C) RDBCI: Rev. Digit. Bibliotecon. Cienc. Inf. & Campinas, SP & v.15 & n.2 & p. 442-468 & maio/ago. 2017 \\
\hline
\end{tabular}


no mínimo há seis meses não houveram postagens e compartilhamentos de informação via Facebook.

Reconhece-se que este tipo de iniciativa leva tempo e dedicação do sujeito, assim como Galvão (2016) comenta que “[...] manter uma página atualizada requer certo planejamento e conhecimento prévio. Os posts devem ser pensados para atingir uma boa taxa de conversão e gerar engajamento." Segundo Sicuro (2016) é necessário que os responsáveis pelas páginas e perfis façam "[...] publicações regulares, pois a consistência é fundamental." Dos usuários que seguem esses perfis, alguns não percebem a ausência dessas postagens, mas outros, certamente, a percebem. Visto que a mediação da informação é uma ação dialógica, que envolve o cuidado (GOMES, 2014) e a atenção dos bibliotecários, deixar a conta do Facebook sem uso por muito tempo, configura-se como descaso em relação aos usuários. Novamente, pondera-se que a manutenção de uma página requer tempo e pessoal qualificado.

O Facebook disponibiliza um recurso em que o responsável pela página ${ }^{6}$ pode programar as postagens para um determinado dia e horário, fazendo com que não tenha a necessidade de estar conectado no momento da postagem. Além de programar é possível também administrar as postagens já programadas, podendo reprogramá-las, editá-las ou excluí-las (FACEBOOK, 2016b). Muitas empresas têm utilizado essa ferramenta para poupar tempo e manter um relacionamento com seus clientes através de suas páginas. Acredita-se que este recurso possa ser uma saída para aquelas bibliotecas que não dispõem de tempo e funcionário para manterse ativos na rede e permanecer presentes nela.

Quanto à periodicidade média dos posts, existem aqueles perfis que postam de duas a quatro vezes por dia: B1, B2, B3, B7, B8; somente uma vez: B4; de duas a três vezes por semana: B9, B11 e apenas uma vez por semana B13.

Dentre as 959 publicações postadas nos perfis localizados, muitos foram os temas e intenções com os conteúdos, que foram categorizados de acordo com a proximidade dos posts. Chegou-se a um total de 15 categorias temáticas, sendo elas:

a) CATEGORIA A - Aquisição de novo material bibliográfico, promoção do acervo e indicação de leituras;

b) CATEGORIA B - Reconhecimento a funcionários da instituição que participam de eventos;

c) CATEGORIA C - Cumprimento aos funcionários e amigos por alguma conquista ou aniversário;

d) CATEGORIA D - Editais de programas de pós-graduação (da IES vinculada ou não);

e) CATEGORIA E - Eventos e cursos (não promovidos pela biblioteca);

f) CATEGORIA F - Eventos, cursos e exposições (promovidos pela biblioteca);

${ }^{6}$ Este recurso está disponível apenas para os perfis do tipo "Páginas".

\begin{tabular}{l|l|l|l|l|l}
\hline (C) RDBCI: Rev. Digit. Bibliotecon. Cienc. Inf. & Campinas, SP & v.15 & n.2 & p. 442-468 & maio/ago. 2017 \\
\hline
\end{tabular}


g) CATEGORIA G - Funcionamento da biblioteca (durante o ano letivo, férias e greve);

h) CATEGORIA H - Informação social e de interesse da comunidade em geral;

i) CATEGORIA I - Link para download gratuito de livros;

j) CATEGORIA J - Links relacionados a Biblioteconomia e CI, anais de eventos (diversas áreas);

k) CATEGORIA K - Memes (relacionados a leitura ou ao contexto das universidades);

1) CATEGORIA L - Prêmios recebidos pela biblioteca ou pela universidade;

m) CATEGORIA M - Publicações periódicas e novos números publicados (editadas ou não pela IES);

n) CATEGORIA N - Sites de pesquisa (base de dados, portais de busca integrada);

o) CATEGORIA O - Vagas de empregos, de estágios e editais de concurso.

Após realizar uma investigação muito próxima, mas com outro universo de pesquisa, Santos e Gomes (2015) chegaram a um total de 16 categorias ao levantar e analisar as ações de mediação da informação no Facebook pelas bibliotecas públicas brasileiras. Já em um outro estudo analisando também as bibliotecas públicas brasileiras, realizado por Almendra (2014 apud CALIL JUNIOR; ALMENDRA, 2016) estabeleceram-se sete categorias. Ao confrontar as categorias definidas neste artigo com aquelas definidas pelas referidas investigações, podese constatar uma tendência temática de postagens entre as contas das bibliotecas, sejam elas universitárias ou públicas. Entre elas, as que mais se repetem são as referentes ao funcionamento da biblioteca e ações por ela desenvolvidas.

Para uma melhor visualização de como foi a distribuição dos conteúdos das postagens analisadas nesta delimitação, o gráfico 2 apresenta a porcentagem com que as categorias indicadas anteriormente aparecem nos posts.

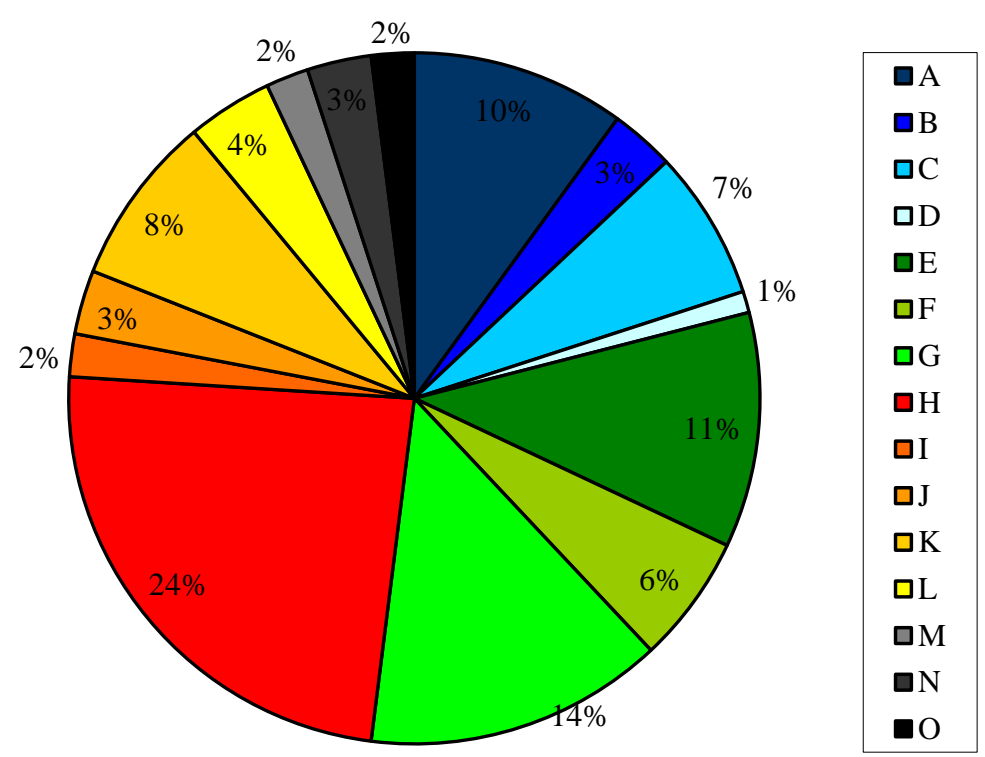

Gráfico 2. Porcentagem das categorias dos posts

Fonte: Dados da pesquisa (2016).

\begin{tabular}{c|c|c|c|c|c}
\hline (C) RDBCI: Rev. Digit. Bibliotecon. Cienc. Inf. & Campinas, SP & v.15 & n.2 & p. 442-468 & maio/ago. 2017 \\
\hline
\end{tabular}


Legenda: As letras de A - O representam as categorias elencadas anteriormente.

Constatou-se que a maioria das postagens se enquadra na categoria $\mathrm{H}$ - Informação social e de interesse da comunidade em geral (24\%). Nela foi observada uma variedade de temas, como dicas de saúde e de moda, locais que prestam serviços ao cidadão, curiosidades, entre outros. Assim como foi constatado por Santos e Gomes (2015) “[...] identificou-se o uso do Facebook para prestação do serviço de informação à comunidade, no que se refere à publicação de informações de interesse geral." O mesmo ocorreu nesta pesquisa.

Com um equilíbrio próximo em relação aos conteúdos, apareceram sequencialmente as categorias G - Funcionamento da biblioteca (14\%), em que se informava horário de atendimento e alterações em datas específicas, como feriados e finais de semana, interrupção dos serviços devido a greves e paralisações ${ }^{7}$; E - Eventos e cursos (11\%), quando as contas publicavam notas de eventos e cursos que não seriam ofertados pela biblioteca ou pela IES vinculada; e, A - Aquisição de novo material bibliográfico, promoção do acervo e indicação de leituras $(10 \%)$, a mediação neste caso era feita visando a socialização das obras que foram recém incorporadas ao acervo da biblioteca, como também objetivando promover a coleção já existente, além de sugerir leituras, científicas ou não. Em seguida, a categoria K - Memes (8\%), que a partir das postagens, as bibliotecas buscavam transmitir mensagens relacionadas a leitura ou a universidade, ao cotidiano do estudante universitário, aos jargões acadêmicos e estereótipos dos cursos, mas de forma criativa e divertida; a categoria D - Editais de programas de pós-graduação (7\%), em que se divulgavam a abertura de editais de cursos de mestrado e doutorado em diferentes áreas do conhecimento; e, F - Eventos, cursos e exposições (6\%), quando as bibliotecas faziam a promoção e divulgação das atividades que eram oferecidas por elas próprias, como palestras, cursos de normalização de trabalhos, exposições de obras raras etc. As demais categorias, contemplaram as postagens que tiveram menor ocorrência, entre $4 \%$ e $1 \%$.

Quanto à expressividade de posts em relação as categorias, pode-se constatar que a conta que mais publicou conteúdos sobre informação social ou de interesse da comunidade, foi a Tecidoteca - Moda UEM. Uma hipótese é que devido ao campus da referida IEES ofertar o Curso de Moda e fazer parte do eixo Maringá-Cianorte, um polo têxtil em expansão, intensificam-se as publicações nesta temática, com a divulgação de informações sobre a indústria têxtil, composição de tecidos, estilos e moda de diferentes épocas. As contas da Bibliotecas Uel e Biblioteca Central Uem são as que mais postaram informações sobre eventos e cursos realizados fora da IES. Já em relação a promoção do acervo e atualização sobre as recentes aquisições, foi o perfil da Biblioteca Setorial - Anos iniciais do Cap/Uem, geralmente

\footnotetext{
${ }^{7}$ A ocorrência de postagens deste tipo deve-se ao momento turbulento e instável, político e econômico, que afeta não só o estado do Paraná, como o Brasil. Este momento coincidiu com o período delimitado para coleta e análise dos dados. Foram constatadas postagens sobre greve e paralisações em 12 das 13 contas do Facebook das bibliotecas universitárias estaduais no período analisado.
}

\begin{tabular}{l|l|l|l|l|l|l}
\hline (C) RDBCI: Rev. Digit. Bibliotecon. Cienc. Inf. & Campinas, SP & v.15 & n.2 & p. 442-468 & maio/ago. 2017 \\
\hline
\end{tabular}


com fotos dos livros e dos autores. Ao se analisar os memes mais postados, constatou-se que a maior quantidade foi a partir de duas contas: Biblioteca Uenp Cche-Clca, e, posteriormente, a BICEN da UEPG. Esta forma de se transmitir mensagens e alertas visando o alcance dos usuários, é uma maneira que difere das demais, visto que os memes são uma forma textual que se utiliza de texto escrito e imagético, facilmente apropriados, especialmente pelo público universitário.

Com o intuito de mensurar a interação entre as contas e os seguidores/amigos, verificouse o número de curtidas, comentários e compartilhamentos nas postagens referentes ao período de análise, maio a outubro de 2016. A tabela a seguir apresenta o total de interações que cada conta obteve no Facebook representado nas colunas pelos ícones das opções curtir, comentar e compartilhar.

Tabela 2. Número de curtidas, comentários e compartilhamentos das postagens

\begin{tabular}{cccc}
\hline NOME NO FACEBOOK & Curtir & Comentar & $\rightarrow$ Compartilhar \\
Bibliotecas UEL & 60 & 8 & 28 \\
Uel Bibliotecas & 102 & 6 & 7 \\
Biblioteca Central Uem & $\mathbf{2 . 1 1 6}$ & $\mathbf{8 7 4}$ & $\mathbf{6 8}$ \\
Biblioteca Crc Uem & 204 & 5 & 23 \\
Biblioteca do Cap Uem & 0 & 0 & 0 \\
Biblioteca Setorial - Anos iniciais do & 36 & 8 & 0 \\
Cap/Uem & 407 & 27 & 61 \\
Tecidoteca - Moda UEM & 1.487 & 87 & 48 \\
Biblioteca Uenp Cche-Clca & 84 & 3 & 11 \\
BICEN & 0 & 0 & 0 \\
Biblioteca Unespar Campus Li - & 155 & 12 & 33 \\
Curitiba/fap & 0 & 0 & 0 \\
Biblioteca Unicentro Cedeteg & 11 & 0 & 0 \\
Biblioteca Cascavel Unioeste & $\mathbf{4 . 8 6 2}$ & $\mathbf{1 . 0 3 0}$ & $\mathbf{2 7 9}$ \\
Biblioteca Unioeste Toledo & & &
\end{tabular}

Fonte: Dados da pesquisa (2016).

Segundo os dados extraídos do Facebook, todas as postagens que foram realizadas pelas contas das bibliotecas universitárias receberam ao todo 4.862 curtidas, 1.030 comentários e 279 compartilhamentos. A conta que obteve o maior número de interação dos usuários nas três possibilidades foi a Biblioteca Central Uem, com 2.116 curtidas, 874 comentários e 68 compartilhamentos. Pode-se observar que as postagens da referida conta que receberam maior interação foram aquelas referentes a categoria $\mathrm{C}$ - Cumprimento aos funcionários e amigos por alguma conquista ou aniversário. Acredita-se que esta interação ocorra devido aos usuários gostarem deste tipo de post e sentirem-se mais à vontade para expressar-se. Outras categorias que apresentaram significante interação foi a $E$ - Eventos e cursos (não promovidos pela biblioteca), principalmente pelas contas da B 1 - Bibliotecas Uel e B 3 - Biblioteca Central Uem e a $\mathrm{G}$ - Funcionamento da biblioteca (durante o ano letivo, férias e greve), por todas as contas.

\begin{tabular}{l|l|l|l|l|l|l}
\hline (C) RDBCI: Rev. Digit. Bibliotecon. Cienc. Inf. & Campinas, SP & v.15 & n.2 & p. 442-468 & maio/ago. 2017 \\
\hline
\end{tabular}


Curiosamente as contas que apresentaram a maior quantidade de postagens não foram na mesma ordem daquelas que obtiveram o maior número de interlocução com os usuários da rede. De acordo com o Facebook (2011), as contas "[...] que postam uma vez por dia apresentam engajamento dos fãs $40 \%$ superior ao das que postam três vezes ou mais." Comparou-se o número de posts com o de interação e chegou-se ao seguinte panorama: a Biblioteca Uenp Cche-Clca com 168 publicações (conta que apresentou o maior número de postagens) recebeu 1.487 curtidas, 87 comentários e 48 compartilhamentos, isto é, segunda com o maior número de interações. A BICEN publicou 160 vezes (segunda conta que mais postou), obteve 84 curtidas, 3 comentários e 11 compartilhamentos, sendo a quarta com mais interlocuções. A Biblioteca Central Uem a partir de 155 postagens (terceira conta que mais postou) foi a que recebeu maior interação dos usuários, conforme dito no parágrafo anterior; e a Bibliotecas UEL com 144 publicações (quarta que mais postou) recebeu 260 curtidas, 8 comentários e 28 compartilhamentos, ocupando a terceira posição entre aquelas com mais interações.

É perceptível que resultado coincidente aparece ao confrontar os dados de interação com o número de amigos ou curtidas que os perfis e páginas possuem. Conforme observado na tabela 1, a página com o maior número de curtidas (2.115), Bibliotecas Uel, obteve a quarta colocação quanto ao nível de interlocução dos usuários. Assim como o perfil com mais amigos, Biblioteca Unicentro Cedeteg (4.997), obteve um retorno baixo de interação dos usuários se comparado àqueles perfis com um menor número de amigos.

Fica evidente, portanto, que o número de interlocução não depende do número de postagens/seguidores/amigos, mas sim dos conteúdos que são mediados na rede, do dia e do momento em que são postados. Segundo Fernandes (2016) quanto mais usuários estiverem online maior é o potencial em alcançá-los, "Afinal, um conteúdo relevante e bem produzido não conseguirá gerar o resultado que merece se não chegar até sua audiência no momento certo." (GALVÃO, 2016). Como o Facebook organiza as postagens segundo uma linha do tempo, isto é, conforme as postagens vão sendo realizadas, se muitas postagens forem feitas em um mesmo horário ou em uma determinada hora do dia, em que há menos usuários online, a chance de visualização e reação (curtida, comentário ou compartilhamento) sobre a postagem pode ser reduzida.

Por outro lado, Sicuro (2016) argumenta que "Hoje em dia essas informações já estão ultrapassadas, pois não importa mais qual dia e horário o Facebook tem mais usuários ativos, mas sim a hora e o dia em que as pessoas que curtiram a página da sua empresa estão online no Facebook." De acordo com algumas pesquisas de mercado, os melhores dias para postar são as quartas e quintas-feiras em torno das 17h (FERNANDES, 2016; GALVÃO, 2016; SICURO, 2016).

\begin{tabular}{c|c|c|c|c|c}
\hline (C) RDBCI: Rev. Digit. Bibliotecon. Cienc. Inf. & Campinas, SP & v.15 & n.2 & p. 442-468 & maio/ago. 2017 \\
\hline
\end{tabular}


Para verificar os momentos em que ocorrem mais interações a rede social disponibilizou uma ferramenta gratuita, intitulada Facebook Insights ${ }^{8}$, que mensura os dados e os resultados que uma conta, mais especificamente uma página, obtém, como: visão geral, curtidas, alcance, visitas, publicações e pessoas. Ressalta-se que estes dados só podem ser visualizados pelos usuários que administram uma conta do tipo "Página".

Reconhece-se que a criação e manutenção de uma conta no Facebook não é suficiente para eliminar as barreiras existentes entre biblioteca, bibliotecário, informação e usuário, no entanto, assim como Bernardino, Suaiden e Cuevas-Cerveró (2014, p. 121) “[...] acreditamos que é o primeiro passo para alcançar o usuário."

Os resultados desta investigação demonstram que houve um aumento no número de contas do Facebook de bibliotecas universitárias estaduais do Paraná, visto que no levantamento realizado em fevereiro e março de 2015, somente sete contas foram identificadas (SANTOS NETO; ALMEIDA JÚNIOR, 2015). Após um ano este número praticamente dobrou, visto que nesta nova coleta foram identificadas 13 contas. Isto demonstra que as unidades de informação estão se atentando cada vez mais às formas de comunicação existentes na $w e b$, deixa claro também o quanto as bibliotecas acreditam no potencial de inovação que uma rede social de relacionamento, como o Facebook, pode apresentar a elas em relação aos serviços e produtos que são oferecidos aos usuários. Feita a análise e discussão dos dados, convida-se o leitor à seção das considerações finais do artigo.

\section{CONSIDERAÇÕES FINAIS}

O objetivo do artigo foi alcançado, pois identificou-se quais são as contas cadastradas no Facebook, oriundas das bibliotecas das IEES do Paraná, que fazem uso desta rede social para mediar a informação. Considera-se que o número de cadastros é relativamente pequeno se comparado ao número total de bibliotecas que constituiu o universo da pesquisa. Do total de 42 bibliotecas, 13 possuem conta cadastrada no Facebook, isto é, aproximadamente 31\% utilizam a rede social para divulgação de conteúdos e interação com os usuários.

Ainda que o número de contas seja baixo em relação ao de bibliotecas existentes, constatou-se que aquelas que aderem ao Facebook para se comunicar e mediar conteúdos aos seus usuários, fazem um uso intenso da rede para tal fim. Dos perfis encontrados, aqueles que atuam mais frequentemente com publicações são oriundos das contas da Biblioteca Uenp CcheClca, BICEN, Biblioteca Central Uem e Bibliotecas UEL. No entanto, observou-se que o número de postagens não é proporcional ao nível de interação estabelecido entre os usuários da rede e a conta, pois as contas que obtiveram maiores índices de participação na rede, isto é, curtidas, comentários e compartilhamentos, foram a Biblioteca Central Uem, Biblioteca Uenp

\footnotetext{
${ }^{8}$ Disponível a partir do link: https://www.facebook.com/insights/.
}

\begin{tabular}{l|c|c|c|c|c}
\hline (C) RDBCI: Rev. Digit. Bibliotecon. Cienc. Inf. & Campinas, SP & v.15 & n.2 & p. 442-468 & maio/ago. 2017 \\
\hline \multicolumn{6}{c}{ [461] }
\end{tabular}


Cche-Clca e Bibliotecas UEL, respectivamente. Ressalta-se, novamente, que o número de amigos no perfil ou de curtidas na página não garante um bom nível de interlocução entre os usuários da rede, visto que a Biblioteca Unicentro Cedeteg, que apresentou o maior número de amigos, não obteve um alto grau de interação dos usuários. Ao mesmo tempo que a Bibliotecas UEL, por possuir o maior número de curtidas em sua página, também não apresentou um elevado retorno dos usuários quanto as suas reações ${ }^{9}$ diante das publicações.

Os conteúdos analisados das postagens são diversos, portanto, foi necessário um agrupamento a partir de 15 categorias temáticas, segundo a proximidade dos textos postados. Dentre elas, a mais explorada foi a categoria H - Informação social e de interesse da comunidade em geral, seguida pela $\mathrm{G}$ - Funcionamento da biblioteca. Porém, as categorias que apresentaram um maior índice de interação dos usuários foram: E - Eventos e cursos (não promovidos pela biblioteca); C - Cumprimento aos funcionários e amigos por alguma conquista ou aniversário; e, G - Funcionamento da biblioteca (durante o ano letivo, férias e greve). Neste artigo não se buscou avaliar a qualidade das postagens, até mesmo porque seria uma tentativa muito audaciosa, visto que uma avaliação sem critérios definidos sempre será subjetiva. $\mathrm{O}$ foco desta investigação foi observar e caracterizar as postagens como forma de mediação da informação, bem como as interlocuções com os usuários do Facebook.

Considera-se que o uso das redes sociais pode oferecer maior visibilidade a essas bibliotecas bem como potencializa as formas de mediação da informação. A partir das publicações postadas, aqueles usuários que não a frequentam podem se interessar e descobrir o que elas têm a oferecer. Por outro lado, aqueles que já utilizam os serviços e produtos da biblioteca, podem tornar-se mais adeptos e fiéis a ela. A interferência, que é deflagrada na mediação da informação a partir do Facebook, influencia, muito possivelmente, na forma como os usuários vão lidar com a informação e no modo como vislumbram o bibliotecário e a biblioteca. As análises das mediações realizadas pelas bibliotecas universitárias permitem compreender " $[\ldots]$ como elas têm construído sua imagem dentro desse dispositivo e ampliado suas relações sociais com os usuários, bem como identificar que os serviços da biblioteca não se restringem ao seu espaço físico, sendo possível também no espaço virtual.” (SANTOS; GOMES, 2015).

A partir da navegação e análise de cada conta foi possível constatar que as bibliotecas universitárias procuram interagir com os seus usuários se utilizando de diferentes linguagens e mídias sociais, como é o caso dos memes. Conforme visto, umas com mais intensidade e frequência e outras menos, porém, todas atentas a necessidade de estar na rede social de relacionamento mais usada no mundo, isto é, próximas aos seus usuários reais e potenciais.

\footnotetext{
${ }^{9} \mathrm{O}$ Facebook permite que os usuários reajam as publicações de outras formas além da opção curtir, isto é possível a partir do clique sobre os emojis que aparecem ao passar o cursor do mouse sobre a opção "curtir", sendo elas: "amei", "haha", "uau", "triste" e "Grr.
}

\begin{tabular}{l|l|l|l|l|l}
\hline (C) RDBCI: Rev. Digit. Bibliotecon. Cienc. Inf. & Campinas, SP & v.15 & n.2 & p. 442-468 & maio/ago. 2017 \\
\hline
\end{tabular}


Defende-se que as bibliotecas tenham que ter um site, de preferência institucional, específico na internet e devam criar contas nas redes sociais, como o Facebook por exemplo. O usuário muitas vezes não possui o hábito de visitar frequentemente o espaço físico da biblioteca, às vezes acessa o seu site, no entanto, se ela estiver inserida na rede social, o alcance será maior e provavelmente o usuário verá o que está sendo postado. Por ser o ambiente de uma universidade, reconhece-se que as necessidades e desejos são distintos e numerosos, mas esse contato mais próximo é possível a partir das interlocuções que a rede social permite, podendo fazer com que os bibliotecários percebam o que é ou não de interesse de sua comunidade, não somente através do tête à tête com os usuários, como também a partir das reações deles na rede. Segundo Novelli, Hoffman e Gracioso (2011) nas unidades informacionais em que a rede social está sendo utilizada, têm ocorrido maior aproximação e apropriação do usuário sobre os conhecimentos buscados na biblioteca.

Acredita-se que as bibliotecas das IEES paranaenses que utilizam o Facebook, estão mediando informação na medida em que além de estabelecer vínculos com os usuários, também compartilham conteúdos para eles. Algumas delas também esclarecem dúvidas e dialogam com os usuários pelo chat. $\mathrm{O}$ que leva à defesa desta posição é a constatação da participação dos usuários nas postagens e compartilhamentos que as bibliotecas realizam no Facebook, seja para avisar sobre o funcionamento da biblioteca, divulgar uma recém aquisição ou sugerir uma leitura. Tendo em vista que na mediação da informação a interferência do bibliotecário fica explícita, conclui-se que ela ocorre também na rede social, interferindo nas decisões do usuário em relação a leitura, consulta, empréstimo etc.

Esta investigação, ainda que acompanhada de um recorte numérico bastante representativo, bem como de uma análise sob óticas diversificadas, abre novas possibilidades de pesquisa quanto a mediação da informação através do Facebook. É necessário investigar se os conteúdos postados na rede atendem e satisfazem a necessidade/desejo dos usuários e, se eles têm se apropriado deles, segundo a definição de mediação da informação de Almeida Júnior (2015), citada anteriormente neste artigo. Em concordância a esta frente de pesquisa, apropria-se do discurso de Amaral e Guimarães (2008), ao afirmarem que "A comunicação assimétrica de uma via dificulta, principalmente, a percepção pelas unidades de informação das necessidades e dos interesses de informação dos seus usuários." Portanto, é fundamental investigar futuramente se essas postagens estão sendo úteis e se são de interesse dos usuários.

Preciso é também, verificar se esta rede tem se apresentado como espaço de aprendizagem, desenvolvimento e inovação, conforme defendem Tomael, Alcará e Di Chiara (2005), em especial porque as bibliotecas universitárias estão em um espaço cujo tripé é formado pelo ensino, pesquisa e extensão. Se presencialmente, já é notada a contribuição das bibliotecas universitárias para esse tripé, faz-se necessário descobrir se o mesmo ocorre remotamente, como no Facebook por exemplo. 


\section{REFERÊNCIAS}

ALMEIDA JÚNIOR, Oswaldo Francisco de. Mediação da informação: um conceito atualizado. In: BORTOLIN, Sueli; SANTOS NETO, João Arlindo dos; SILVA, Rovilson José da (Org.). Mediação oral da informação e da leitura. Londrina: Abecin, 2015. p. 9-32.

AMARAL, Sueli Angélica do; GUIMARÃES, Tatiara Paranhos. Websites de unidades de informação como ferramentas de comunicação com seus públicos. Enc. Bibli: R. Eletr. Bibliotecon. Ci. Inf., Florianópolis, v. 13, n. 26, jul./dez. 2008. Disponível em: <https://periodicos.ufsc.br/index.php/eb/article/view/1518-2924.2008v13n26p147/6642>. Acesso em: 10 nov. 2016.

ARAÚJO, Carlos Alberto Ávila. Mediação como conceito potencializador do diálogo entre a Ciência da Informação e os campos da Arquivologia, Biblioteconomia e Museologia. In: ENCONTRO NACIONAL DE PESQUISA EM CIÊNCIA DA INFORMAÇÃO (ENANCIB), 13., 2012. Rio de Janeiro. Anais eletrônicos... Rio de Janeiro: ENANCIB, 2012. Disponível em: <http://www.eventosecongressos.com.br/metodo/enancib2012/arearestrita/pdfs/19256.pdf $>$. Acesso em: 21 out. 2016.

BARDIN, Laurence. Análise de conteúdo. 3.ed. Lisboa: Edições 70, 2004.

BERNARDINO, Maria Cleide Rodrigues; SUAIDEN, Emir José; CUEVAS-CERVERÓ, Aurora. O uso do Facebook pelas Bibliotecas Públicas do estado do Ceará. InCID: R. Ci. Inf. e Doc., Ribeirão Preto, v. 5, n. 1, p. 112-123, mar./ago. 2014. Disponível em: <http://www.revistas.usp.br/incid/article/view/64334/82236>. Acesso em: 15 nov. 2016.

CALIL JUNIOR, Alberto; ALMENDRA, Gabriela. As apropriações do Facebook pelas bibliotecas públicas estaduais brasileiras. Em Questão, Porto Alegre, v. 22, n. 1, p. 188-213, jan./abr. 2016. Disponível em: <http://seer.ufrgs.br/index.php/EmQuestao/ article/view/54826/35431>. Acesso em: 19 nov. 2016.

COSTA, Maria de Fátima Oliveira; ALMEIDA JÚNIOR, Oswaldo Francisco de. Os conceitos de estudos de usuários e a visão do bibliotecário no processo de mediação da informação. In: CAVALCANTE, Lidia Eugenia; PINTO, Virgínia Bentes; VIDOTTI, Silvana Aparecida Borsetti Gregório. (Org.). Ciência da informação e contemporaneidade: tessituras e olhares. Fortaleza: UFC, 2012. p. 59-87.

DAVALLON, Jean. A mediação: a comunicação em processo?. Prisma.com, Porto, n. 4, 2007. Disponível em: 〈http://revistas.ua.pt/index.php/prismacom/article/viewFile/645/pdf >. Acesso em: 12 out. 2016.

\begin{tabular}{l|c|c|c|c|c}
\hline (C) RDBCI: Rev. Digit. Bibliotecon. Cienc. Inf. & Campinas, SP & v.15 & n.2 & p. 442-468 & maio/ago. 2017 \\
\hline \multicolumn{6}{c}{ [464] }
\end{tabular}


FACEBOOK. Central de ajuda. 2016a. Disponível em: 〈https://www.facebook.com/help/> . Acesso em: 6 nov. 2016.

FACEBOOK. Como faço para programar uma publicação e administrar as publicações programadas em minha Página? 2016b. Disponível em:

<https://www.facebook.com/help/389849807718635?helpref=uf_permalink>. Acesso em: 19 nov. 2016.

FACEBOOK. Glossário de termos. 2016c. Disponível em:

<https://www.facebook.com/help/219443701509174>. Acesso em: 02 nov. 2016.

FACEBOOK. Você sabe quais são os melhores horários para postar no Facebook? 2011.

Disponível em: <https://www.facebook.com/notes/internet-innovation/voc\%C3\%AA-sabequais-s\%C3\%A3o-os-melhores-hor\%C3\%A1rios-para-postar-nofacebook/292920627387823/>. Acesso em: 19 nov. 2016.

FERNANDES, André Bartholomeu. Você sabe qual é o melhor horário para postar no Facebook? Um experimento parece ter a resposta. 2016. Disponível em:

$<$ http://www.jornaldoempreendedor.com.br/destaques/qual-o-melhor-horario-para-postar-nofacebook/>. Acesso em: 21 nov. 2016.

GALVÃO, Raíssa. Descubra o melhor horário para postar no Facebook e quais posts geram mais engajamento! 2016. Disponível em: <http://marketingdeconteudo.com/melhorhorario-para-postar-no-facebook/>. Acesso em: 21 nov. 2016.

GOMES, Henriette Ferreira. A dimensão dialógica, estética, formativa e ética da mediação da informação. Inf. Inf., Londrina, v. 19, n. 2, p. 46-59, maio/ago. 2014. Disponível em: <http://www.uel.br/revistas/uel/index.php/informacao/article/view/19994/pdf_30>. Acesso em: 30 out. 2016.

GOMES, Henriette Ferreira; SANTOS, Raquel do Rosário. A mediação da informação e bibliotecas universitárias: a situação do uso dos dispositivos de comunicação da web social. In:

ENCONTRO NACIONAL DE PESQUISA EM CIÊNCIA DA INFORMAÇÃO (ENANCIB), 12., 2011, Brasília. Anais... Brasília: Unb/Ancib, 2011, p. 830-846.

GOMES, Henriette Ferreira; SANTOS, Raquel do Rosário. Bibliotecas universitárias e a mediação da informação no ambiente virtual: informações, atividades e recursos de comunicação disponíveis em sites. In: ENCONTRO NACIONAL DE PESQUISA EM CIÊNCIA DA INFORMAÇÃO (ENANCIB), 10., 2009, João Pessoa. Anais eletrônicos... João Pessoa, 2009. Disponível em:

\begin{tabular}{l|c|c|c|c|c}
\hline (C) RDBCI: Rev. Digit. Bibliotecon. Cienc. Inf. & Campinas, SP & v.15 & n.2 & p. 442-468 & maio/ago. 2017 \\
\hline \multicolumn{6}{c}{ [465] }
\end{tabular}


<http://enancib.ibict.br/index.php/enancib/xenancib/paper/viewFile/3208/2334>. Acesso em: 15 out. 2016.

KAZENIAC, Andy. Social networks: facebook takes over top spot, twitter climbs. 2009. Disponível em: <https://blog.compete.com/2009/02/09/facebook-myspace-twitter-socialnetwork/>. Acesso em: 7 jun. 2016.

MANESS, Jack M. Teoria da biblioteca 2.0: web 2.0 e suas implicações para as bibliotecas. Info. \& Soc: Est., João Pessoa, v. 17, n. 1, p. 43-51, jan./abr. 2007. Disponível em: <http://periodicos.ufpb.br/ojs2/index.php/ies/article/view/831/1464>. Acesso em: 06 out. 2016.

MARCONI, Marina de Andrade; LAKATOS, Eva Maria. Técnicas de pesquisa: planejamento e execução de pesquisas, amostragens e técnicas de pesquisas, elaboração, análise e interpretação de dados. 7. ed. São Paulo: Atlas, 2011.

MARTELETO, Regina Maria. Jovens, violência e saúde: construção de informação nos processos de mediação e apropriação de conhecimentos. RECIIS: R. Eletr. de Com. Inf. Inov. Saúde. Rio de Janeiro, v. 3, n. 3, p. 17-24, set. 2009. Disponível em: $<$ http://www.reciis.icict.fiocruz.br/index.php/reciis/article/view/751/1393 > . Acesso em: 04 out. 2016.

NOVELLI, Valéria Aparecida Moreira; HOFFMANN, Wanda Aparecida Machado; GRACIOSO, Luciana de Souza. Mediação da informação em websites de bibliotecas universitárias brasileiras: referencial teórico. Inf. Inf., Londrina, v. 16, n. 3, p. 142-166, jan./jun. 2011. Disponível em:

<http://www.uel.br/revistas/uel/index.php/informacao/article/view/8357/10591>. Acesso em: 10 set. 2016.

SANTARÉM SEGUNDO, José Eduardo. A documentação: Paul Otlet e o Facebook. In: CRIPPA, Giulia; MOSTAFA, Solange Puntel (Org.). Ciência da informação e documentação. Campinas: Alínea, 2011. p. 99-112.

SANTOS NETO, João Arlindo dos. Mediação implícita da informação no discurso dos bibliotecários da Biblioteca Central da Universidade Estadual de Londrina (UEL). 193f. 2014. Dissertação (Mestrado em Ciência da Informação) - Universidade Estadual Paulista "Júlio de Mesquita Filho", Faculdade de Filosofia e Ciências, Campus de Marília/SP, 2014. Disponível em: < https://www.marilia.unesp.br/Home/PosGraduacao/CienciadaInformacao/Dissertacoes/santos_neto_jad_me_mar.pdf $>$. Acesso em: 10 set. 2016.

\begin{tabular}{c|c|c|c|c|c}
\hline C) RDBCI: Rev. Digit. Bibliotecon. Cienc. Inf. & Campinas, SP & v.15 & n.2 & p. 442-468 & maio/ago. 2017 \\
\hline
\end{tabular}


SANTOS NETO, João Arlindo dos; ALMEIDA JÚNIOR, Oswaldo Francisco de. A mediação da informação e o uso das redes sociais pelas bibliotecas universitárias estaduais do Paraná. In: SEMINÁRIO CIENTÍFICO ARQUIVOLOGIA E BIBLIOTECONOMIA, 4., 2015, Marília. Anais... Marília: Oficina Universitária, 2015. p. 1-10. (CD-R)

SANTOS NETO, João Arlindo dos; BORTOLIN, Sueli. Mediação da informação: afinando o foco na Arquivologia. In: ENCONTRO DA ASSOCIAÇÃO DE EDUCAÇÃO E PESQUISA EM CIÊNCIA DA INFORMAÇÃO DA IBEROAMÉRICA E CARIBE (EDICIC), 10., 2016, Belo Horizonte. Anais... Belo Horizonte: UFMG, 2016.

SANTOS, Bruna Bomfim Lessa dos; GOMES, Henriette Ferreira. Bibliotecas públicas do Brasil e o uso de dispositivos de comunicação da web social: o Facebook como espaço de mediação da informação. In: ENCONTRO NACIONAL DE PESQUISA EM CIÊNCIA DA INFORMAÇÃO (ENANCIB), 16., 2015, João Pessoa. Anais eletrônicos... João Pessoa: UFPB/Ancib, 2016. Disponível em: $<$ http://www.ufpb.br/evento/lti/ocs/index.php/enancib2015/enancib2015/paper/viewFile/3119 /1053 >. Acesso em: 18 nov. 2016.

SICURO, Pedro. Qual o melhor horário para postar no Facebook? 2016. Disponível em: $<$ http://www.administradores.com.br/artigos/marketing/qual-o-melhor-horario-para-postarno-facebook/96202/>. Acesso em: 18 nov. 2016.

SIGNATES, Luiz. Estudo sobre o conceito de mediação. Novos Olhares: Revista de Estudos sobre Práticas de Recepção a Produtos Midiáticos - ECA/USP, São Paulo, n. 2, jul./dez. 1998. Disponível em: <http://www.revistas.univerciencia.org/index.php/novosolhares/article/viewFile/8311/7694>. Acesso em: 03 nov. 2016.

TOMAÉL, Maria Inês. Redes sociais, conhecimento e inovação localizada. Inf. Inf., Londrina, v. 12, n. esp., 2007. Disponível em: <http://www.uel.br/revistas/uel/index.php/informacao/article/view/1782/1519>. Acesso em: 04 nov. 2016.

TOMAÉL, Maria Inês; ALCARÁ, Adriana Rosecler; DI CHIARA, Ivone Guerreiro. Das redes sociais à inovação. Ci. Inf., Brasília, v. 34, n. 2, p. 93-104, maio/ago. 2005. Disponível em: 〈http://www.scielo.br/pdf/ci/v34n2/28559.pdf >. Acesso em: 03 nov. 2016.

TOZONI-REIS, Marília Freitas de Campos. A pesquisa e a produção de conhecimentos. In: UNIVERSIDADE ESTADUAL PAULISTA - PRÓ-REITORIA DE GRADUAÇÃO.

Caderno de formação: formação de professores: educação cultura e desenvolvimento. v. 3. São Paulo: Cultura Acadêmica, 2010. p. 111-148. Disponível em: 〈http://www.acervodigital.unesp.br/handle/123456789/192>. Acesso em: 05 nov. 2016.

\begin{tabular}{l|c|c|c|c|c}
\hline (C) RDBCI: Rev. Digit. Bibliotecon. Cienc. Inf. & Campinas, SP & v.15 & n.2 & p. 442-468 & maio/ago. 2017 \\
\hline \multicolumn{6}{c}{ [467] }
\end{tabular}


VAZ, Paulo. Mediação e Tecnologia. Famecos, Porto Alegre, n. 16, dez. 2006, p. 45-59. Disponível em: <http://revistaseletronicas.pucrs.br/ojs/index.php/revistafamecos/article /viewFile/3137/2408 >. Acesso em: 15 nov. 2016.

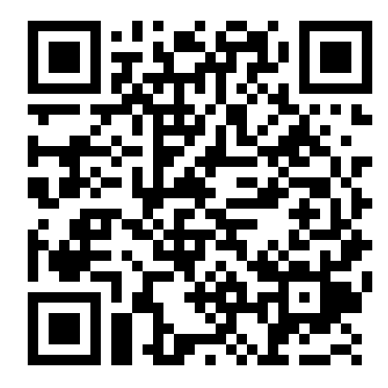

g

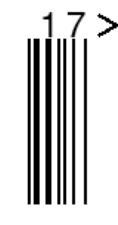

